\title{
El diario del doctor José Felipe Flores: viajes por Europa, ciencias y escritura
}

The diary of the doctor José Felipe Flores: travels through Europe, sciences and writing

Emilie Cadez Ortola

Centro de Estudios Ibéricos e Iberoamericanos (CEIIBA, EA 7412) Universidad de Toulouse Jean Jaurès 


\section{RESUMEN}

José Felipe Flores es uno de los científicos del siglo XVIII más olvidados hoy en día. Sin embargo, siempre estuvo muy activo en varios ramos de las ciencias. Obró además por el desarrollo del conocimiento científico en Guatemala. Por eso quiso viajar por Europa. De este periplo quedan algunas cartas y un diario, inédito y desconocido hasta hoy, debido a una equivocada identificación de su autor.

En este artículo, es este diario el que vamos a glosar y analizar. Trataremos la cuestión de su autor y de su historia y estudiaremos su dimensión científica, con la mención que en él se hace de los avances científicos y de los sabios con los cuales se encuentra el doctor Flores.

Palabras clave

Flores, Ciencias, Viajes, Redes, Guatemala, Europa.

\section{AbSTRACT}

José Felipe Flores is one of the scientists of the eighteenth century who is totally forgotten by now. However, he always was very active in several sections of the scientific domain. Moreover, he always did what he could for the development of the scientific knowledge in Guatemala. That is why he travelled through Europe. Of this travel, he left letters and a diary, unpublished and unknown until today, because of a wrong identification of its author.

With this article, we intend to study this particular diary. After the evocation of its author and its history, we will observe its scientific dimension, with the mentions of the scientific development and of the contacts between the Guatemalan doctor and the European scientists.

\section{Key Words}

Flores, Sciences, Travels, Networks, Guatemala, Europe.

Recibido: 16 de enero de 2020. Aceptado: 11 de marzo de 2020.

Este artículo se enmarca en un proyecto de edición crítica del diario del viaje de José Felipe Flores. Las temáticas que aquí abordamos las desarrollaremos en la Introducción a dicha edición, cuya publicación está prevista para el año 2020. 


\section{Introducción}

José Felipe Flores nace en 1751 en Ciudad Real de Chiapas ${ }^{1}$, situada en aquella época en Guatemala, y que pertenece hoy a la república de México. Bachiller en Filosofía y en Medicina por la Universidad de San Carlos de Guatemala, se doctora en Medicina en 1780. Mientras tanto, a partir de 1774, José Felipe Flores empieza a ser médico en el Hospital de San Juan de Dios. Se encarga de dicho hospital hasta 1778. Después de su traslado a la Nueva Guatemala, tras el terremoto que destruyó gran parte de la Antigua Guatemala en 1773, vuelve a encargarse de él entre 1779 y 1781, año en que es nombrado Médico fijo del Real Hospital. Se reconoce la gran implicación de Flores al servicio de los enfermos. En las epidemias de tifo, no cuenta sus horas de trabajo, pero demuestra su verdadero protagonismo en el ámbito de la Medicina durante la gran epidemia de viruelas de 1780. Los resultados exitosos de sus experimentos constituyen un hito fundamental en su vida ya que le valen el reconocimiento de sus pares y también de la esfera política de la Audiencia de Guatemala. Estos permiten también avances innegables en el campo de la investigación sobre la vacuna, lo que más tarde llevará a Francisco Javier Balmis a contactar con él para sus competencias y sus conocimientos a la hora de preparar su Real Expedición Filantrópica de la Vacuna (1803-1804). En la misma época, el doctor Flores lleva experimentos para intentar contrarrestar otras enfermedades, como el cáncer que, según él, se curaría ingiriendo albóndigas de cierta especie de

1 Para realizar el breve recorrido biográfico que aquí proporcionamos, hemos consultado las fuentes manuscritas siguientes: [Carrera y cargos universitarios de Flores. 29 de octubre de 1792], Archivo General de Indias, Guatemala, 579, Exp. 8, ff. 99r-100r.; [El Cabildo presenta los méritos de Flores. 19 de octubre de 1792], Archivo General de Indias, Guatemala, 579, Exp. 8, ff. 1v.-9r.; [Expediente de Flores en la Universidad de San Carlos, copiado por su Secretario Archivero, don Esteban José Pérez. 24 de octubre de 1792], Archivo General de Indias, Guatemala, 579, Exp. 8, ff. 106r.-118r.; [Flores recibe los honores de Médico de Cámara Honorario y una pensión de 1200 pesos. 16 de abril de 1794], Archivo General de Indias, Guatemala, 649.

Véanse también: Mariano PADILLA, «Biografía del Dr. D. José Flores», Mensual de la Sociedad de Medicina de la República de Guatemala, 1847 (2), págs. 14-18; Francisco Asturias, «José Felipe Flores», Historia de la medicina en Guatemala, Guatemala, Tipografía Nacional, 1902, págs. 463-489; Carlos MartínEz DurÁN, Las ciencias médicas en Guatemala. Origen y evolución, Guatemala, Tipografía Nacional, 1945, págs. 258315; José Aznar López, El Doctor Don José de Flores. Una vida al servicio de la ciencia, Guatemala, Editorial universitaria, 1960. 
lagarta endémica de la zona del lago Amatitlán. Demuestra sus supuestas virtudes curativas en su Específico nuevo para la curación radical del horrible mal del cancro, y otros más frecuentes ${ }^{2}$, publicado en 1782. Este tratado lo lleva a ser conocido en Europa, por ser traducido al francés, al alemán, al inglés y al italiano.

En 1783, el ya famoso y reconocido doctor don José Felipe Flores consigue la Cátedra de Prima de Medicina de la Universidad de San Carlos. Tanto sus contemporáneos como los investigadores del siglo xx concuerdan en decir que, si su gran amigo fray Juan Antonio Goicoechea renovó los estudios en la Universidad de San Carlos en general, José Felipe Flores les da un nuevo y fuerte impulso a los estudios de Medicina en particular. De hecho, se le considera como el padre de la Medicina y de los estudios médicos en Guatemala. El que también desempeña cargos de Conciliar y Diputado de Hacienda en su Universidad proporciona muchos recursos nuevos para la enseñanza de la Medicina y se dedica plenamente al progreso de sus discípulos, sin dejar de lado sus obligaciones de médico en los hospitales y cárceles de la ciudad. En su casa reúne una amplia colección de libros, máquinas e instrumentos, que inventa, compra o copia a sus expensas. Lleva a sus estudiantes a no limitarse al campo estrictamente médico y a estudiar la botánica, la mecánica, la física y la química, porque entiende los muchos paralelismos que existen entre fenómenos de estos campos y lo que se puede observar en el cuerpo humano. Flores es muy consciente de la necesidad de dominar la anatomía, no sólo en la teoría de los libros sino también en práctica, pero se enfrenta a problemas pragmáticos que impiden que sus discípulos efectúen las disecciones, las manipulaciones y los experimentos necesarios. Para remediar el problema, realiza, otra vez a su costa, estatuas de cera que representan muy detalladamente y al natural el cuerpo humano (esqueleto, musculatura, nervios, circulación sanguínea, etc.) enteramente articuladas, armables y desarmables. Realiza la primera estatua en 1789, y en 1792 ya tiene tres y está trabajando en la realización de un cuerpo de mujer ${ }^{3}$. Desafortunadamente, dichas estatuas no se han conservado ${ }^{4}$.

En relación con este afán de desarrollo de la Medicina y con esta lucha por una mejor formación de los médicos y cirujanos, Flores obra también, a principios de los años 1790, por la creación de un Tribunal de Protomedicato en Guatemala. En tanto Catedrático de Prima de Medicina, Flores ya ejerce este cargo de manera informal, puesto que las funciones de Protomédico suelen ser

2 José Felipe FLores, Específico nuevo para la curación radical del horrible mal del cancro, y otros más frecuentes, Madrid, Por Doña María Razola, Calle de la Cruz, 1782, 22 págs.

3 [Informe de Joaquín Viejobueno sobre los esqueletos de cera de Flores. 30 de octubre de 1792], Archivo General de Indias, Guatemala, 649.

4 Aznar López, pág. 49. 
asociadas a dicha Cátedra en otros lugares del imperio español. En 1793, la Corona decide la fundación del Protomedicato, dándole así a la labor de Flores en este ámbito un marco oficial.

La mayoría de sus costosas labores las realiza Flores cobrando rentas poco elevadas, o incluso sin cobrar ninguna. Para poder seguir trabajando, y en recompensa de sus méritos, solicita el cargo de Médico de Cámara Honorario del Rey Carlos IV. Se le concede por Real Orden del 16 de abril de 1794, asociado con una renta anual de 1200 pesos fuertes del fondo de Comunidades de Indios, con la condición de que ceda sus libros, máquinas, instrumentos y estatuas de cera a la Universidad de San Carlos ${ }^{5}$.

Sin embargo, el mundo de José Felipe Flores se le está quedando pequeño. Tiene conciencia de que no todos los saberes científicos llegan a Guatemala y de que su patria chica, la «gurupera del mundo» como a veces la llama ${ }^{6}$, se está quedando atrás. Por eso, el 23 de noviembre de 1795 solicita un permiso para viajar a España. Quiere ir más allá de los límites impuestos por la mera consulta de los libros que llegan a su alcance y ver con sus propios ojos los avances científicos que tienen lugar en Europa, y contactar con los científicos del Viejo Continente, como lo explica en su solicitud de permiso:

Para corresponder pues con la perfección que merece la beneficencia del Soberano, y poder dar la última mano, no sólo a Medicina y Cirugía, sino a las demás Ciencias Subalternas, y hacerme más útil a este Reino, en cuyas dilatadas Provincias la naturaleza ha derramado a manos llenas sus dones, he considerado que no me bastan los libros, y las noticias: y que para cumplir mis deseos era preciso hacer un viaje a España a ver los Gabinetes, los Laboratorios, y los Jardines: y a hablar y conocer a los grandes Profesores. Estoy persuadido que con los principios que tengo conseguiría en aquel mundo con la vista y la voz viva infinita instrucción, prácticas y experiencias: y me haría verdaderamente capaz de recogerlas y traerlas a esparcir a este Reino con grande utilidad de estos y de aquellos dominios $[\ldots]^{7}$

El 10 de junio de 1796, recibe el Real Permiso para viajar a España y se

5 [Flores recibe los honores de Médico de Cámara Honorario y una pensión de 1200 pesos. 16 de abril de 1794], Archivo General de Indias, Guatemala, 649.

6 Estos términos aparecen en una carta que Flores escribe desde Filadelfia a fray José Antonio Goicoechea, fechada de 17 de mayo de 1797 «de suerte que si como yo he vivido en la gurupera del mundo hubiera estado en otra parte, yo hubiera hecho más de una fachendada». MARTínEz Durán, pág. 305. Desafortunadamente, no hemos podido acceder a la versión original de dicha carta.

7 [Solicitud de Flores para un viaje a España. 23 de noviembre de 1795], Archivo General de Indias, Guatemala, 649. 
le concede licencia para cuatro años ${ }^{8}$. Para este viaje pide la protección de don Eugenio de Llaguno y Amírola, Secretario de Gracia y Justicia, y del Príncipe de la Paz, don Manuel Godoy, Secretario de Estado9. El 23 de noviembre de 1796, sale de la Nueva Guatemala. Deja la América española pasando por Trujillo y Cuba. Hace una parada en Filadelfia, antes de llegar al Viejo Continente, donde recorre el norte de Europa, Inglaterra, Francia, Italia y España. Durante este viaje, como lo veremos más adelante, entra en contacto con muchos científicos y se interesa por todos los ramos de la ciencia, incluso por la física óptica, lo que lo incita a instalarse en La Granja en 1799 para realizar experimentos en este ámbito y elaborar un telescopio, comprando con financiación propia el material necesario en la Fábrica de Cristales ${ }^{10}$.

Si la mayor parte de su labor es bastante conocida, el desarrollo de su viaje lo es por las cartas que Flores envía a sus corresponsales en España y en Guatemala - por ejemplo, su amigo fray Juan Antonio Goicoechea-, algunas de las cuales fueron publicadas en la Gaceta de Guatemala ${ }^{11}$. Hasta el momento, dichas cartas eran el único testimonio de los desplazamientos del médico por Europa...

\section{Un diario desconocido: el manuscrito 17730}

El manuscrito 17730 de la Biblioteca Nacional de España, de una extensión de 72 folios, que sirve de fundamento a este trabajo, es el último tomo del diario de viaje de José Felipe Flores. Desafortunadamente, todavía no se ha podido localizar el o los tomos anteriores. Aparece en los repertorios de la Biblioteca Nacional como Viaje descriptivo a Italia, Francia y España, escrito alrededor de los años 1801-1802 por José de Torres. Procede de los fondos de Pascual de Gayangos cedidos a la BNE después de la muerte del coleccionista, según las informaciones presentes en estos repertorios ${ }^{12}$, sacadas del catálogo

${ }^{8}$ [Real permiso para el viaje de Flores a España. 10 de junio de 1796], Archivo General de Indias, Guatemala, 649.

9 [Flores pide protección a Manuel Godoy y a Eugenio de Llaguno y Amírola. Noviembre de 1796], Archivo General de Indias, Guatemala, 649.

10 [Relación de la representación de Flores de 8 de abril de 1801. 18 de mayo de 1801], Archivo General de Indias, Guatemala, 649.

11 Desafortunadamente no hemos podido localizarlas, pero algunas de estas cartas están copiadas, parcial o integralmente, en la bibliografía ya mencionada.

12 http://catalogo.bne.es/uhtbin/cgisirsi/?ps=56Tis3RTRd/BNMADRID/15940452/9\#ejemplares [Fecha de última consulta: 25.04.2020] 
establecido por Pedro Roca en $1904^{13}$. Para realizar la noticia bibliográfica que corresponde a este manuscrito, Roca se fundó en su portada ${ }^{14}$. Sin embargo, dicha portada, que podría aportar valiosas indicaciones, no es autógrafa e induce varios problemas. Primero se da a este documento un título a posteriori: Viaje descriptivo de N. Habla de Roma y demás ciudades de Italia, y de Francia, París, España, establecimientos y mejoras de la Fábrica de Cristales de La Granja: En forma de diario escrito originalmente por el mismo. Es parcialmente erróneo, sobre todo en cuanto a la Fábrica de Cristales: con este título se supone que Flores propone mejoras de dicha instituciones, pero no es el caso. En cuanto a la mención «N.», no se sabe ni a qué ni a quién corresponde. Es más, al observar la disposición de la página y la grafía empleada, tampoco podemos afirmar que dicha letra no haya sido añadida al título en un segundo tiempo, ya que parece dejarse espacio para un nombre completo más largo. Luego, en una nota de otra mano, acompañada de la firma y sello de Gayangos, se puede leer: «El autor de este viaje se llamaba D. Joseph de Torres, y era profesor de Óptica en Guatemala. Vino a España ofreciendo hacer a su costa un telescopio, como lo ejecutó en el año de 1801». Este comentario proporciona una primera identificación, pero conlleva tres errores: la profesión del viajero así como el motivo de su viaje $^{15}$ son distintos - lo que Gayangos no hubiera podido deducir sólo con leer el diario—, y, sobre todo, la identidad misma del autor es errónea. En efecto, la única mención del nombre del autor se halla en el folio 59r., que corresponde al día 19 de agosto de 1799, en el cual en realidad se indica:

Se pasó oficio del Ministerio de Estado al de Hacienda, de quien depende la Fábrica de Cristales, y este Ministerio pasó orden al Director de la Fábrica diciendo: que a Don José de Flores, profesor de Óptica, que se ofreció hacer a su costa un telescopio, se le diesen todos los auxilios necesarios.

13 Pedro Roca, Catálogo de los manuscritos que pertenecieron a don Pascual de Gayangos existentes en la Biblioteca Nacional, Madrid, Tipografía de la Revista de Archivos, Bibliotecas y Museos, 1904.

14 Véase Anexo 1.

15 Aunque la mención al telescopio aparece ya en la portada del manuscrito, su elaboración no es la meta principal del viaje de Flores, tal como él mismo lo expone en un memorial fechado de 18 de mayo de 1801 : «En uno de estos cursos [de las ciencias en París], en que se trataba de óptica, hizo Flores algunas experiencias para mejor los telescopios de reflexión, las cuales le salieron tan acertadas, que al regreso a España se propuso seguirlas, considerándolas del mayor interés para las ciencias. Con el propósito de verificar sus tentativas y resolver un problema nuevo y sumamente difícil se presentó Flores en el sitio de San Ildefonso, ofreciendo a Vuestra Majestad por el Ministerio de Estado hacer un espejo grande, si se le facilitaban en las fábricas de cristal los materiales necesarios; y aunque se tuvo por impracticable el proyecto, se le mandaron entregar y con efecto se le entregaron los materiales, pagando todo Flores a los precios corrientes». [Memorial de Flores de 18 de mayo de 1801], Archivo General de Indias, Guatemala, 649. 


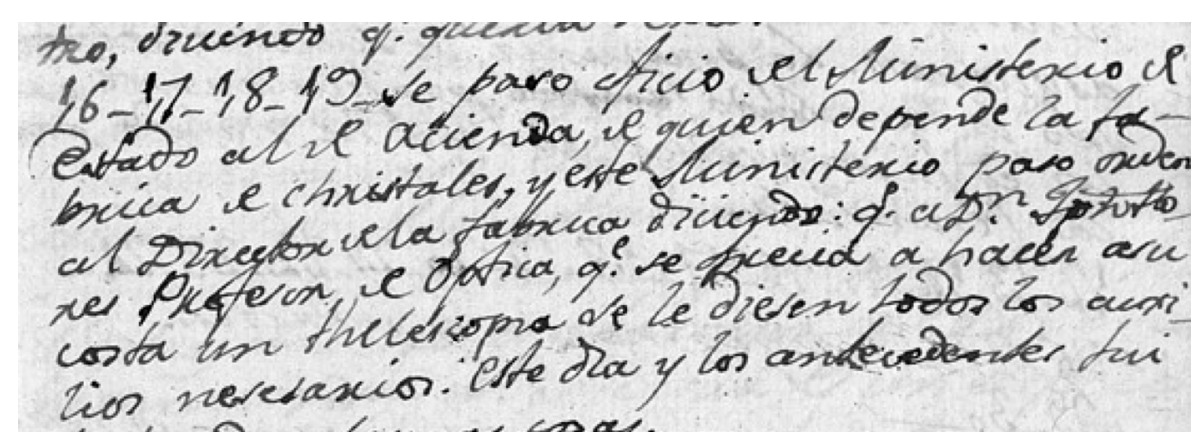

Fig. 1: Fragmento del folio 59 r.

Comprobamos la autoría de «Joseph de Flores», o José Felipe Flores, mediante el estudio de otros manuscritos autógrafos, como por ejemplo un memorial conservado en el Archivo Histórico Nacional ${ }^{16}$, en los que concuerdan la letra y la firma del médico, así como su manera de abreviar su nombre. Además, las informaciones contenidas en el diario también concuerdan con elementos sacados de otros manuscritos de y acerca de Flores, así como de la bibliografía posterior relativa a su vida y obra. Esta equivocada atribución, debida sin duda a un error de lectura del manuscrito, tuvo repercusiones en el catálogo de Roca primero, y luego en los registros de la BNE, como lo acabamos de ver. Del mismo modo aparece en la Bibliografía de Autores del Siglo XVIII de Francisco Aguilar Piñal, y en los catálogos biobibliográficos de Carlos García-Romeral Pérez ${ }^{17}$. De allí que, hasta hoy, nunca se supo de la existencia de un diario de viaje del Doctor Don José Felipe Flores.

Este diario corresponde al período del 20 de mayo de 1798 al 23 de noviembre de 1802. Flores apunta pues en él parte de su viaje por Italia, así como su segunda estancia en Francia y en España. El diario empieza con el relato de su estancia en Florencia. El médico se dirige luego hacia el sur y reside durante algunos días en Roma, y después en Nápoles. A mediados del mes de junio de 1798, sale de Nápoles y vuelve a Roma, cruza la península italiana para ir al norte por la costa del Adriático y por fin llega a Venecia. De allí, emprende

16 Flores, [Flores da una noticia exacta de sus trabajos. 5 de mayo de 1809], Archivo Histórico Nacional, Estado, 3082, Exp. 25, ff. 45-51.

17 Francisco Agullar Piñal, Bibliografía de Autores Españoles del Siglo XVIII, tomo VIII, Madrid, CSIC, 1995, pág. 92.

Carlos García-Romeral Pérez, Diccionario de viajeros españoles. Desde la Edad Media a 1970, Madrid, Ollero \& Ramos, 2004, pág. 437.

García-Romeral Pérez, Diccionario biobibliográfico de viajeros por España y Portugal, Madrid, Ollero \& Ramos, 2010, pág. 378 . 
camino hacia el oeste y sale de Italia el 17 de julio de 1798, pasa por Suiza y Saboya para llegar a París. Se queda en la capital francesa del 27 de julio de 1798 al 26 de mayo de 1799. Luego se encamina hacia Orléans y Burdeos, y pasa el Bidasoa el 10 de junio. Viaja por Pamplona y Tudela, navega por el Canal Imperial para ir a Zaragoza, y entra en Madrid el 27 de junio. El 6 de agosto del mismo año de 1799, se le ordena acudir a la Fábrica de Cristales de La Granja, donde residirá durante varios años, por lo menos hasta el 23 de noviembre de $1802^{18}$.

Las temáticas abordadas en el diario de Flores son de índole muy variada. Además de informaciones propias del viaje (lugares, distancias o incidentes ocurridos durante el trayecto), el diario adquiere un valor testimonial mediante una innegable dimensión política en la medida en que, por una parte, el viajero alude muy a menudo al contexto geopolítico europeo y, por otra parte, porque se nota a veces una fuerte carga crítica en los propósitos del autor, lo cual revela su gran implicación en la polis.

En menor medida, concentradas en las entradas relativas a la estancia del autor en Italia, se pueden notar referencias a la Historia, así como un interés por las Bellas Artes (Pintura, Escultura, Arquitectura, Música, ...).

Este texto tiene también una fuerte dimensión científica, no sólo porque se relatan, en el último tercio del documento, experimentos acerca del telescopio realizado con los cristales de la Fábrica de la Granja, sino también porque se hace manifiesto a lo largo del manuscrito el gran interés de Flores por las ciencias de todo tipo (Medicina, Anatomía, Botánica, Física, Química, Óptica, Mecánica, ...). Esta dimensión se evidencia mediante las numerosas alusiones a centros científicos y fábricas, máquinas e instrumentos, descubrimientos y avances, reflexiones críticas para mejorar instrumentos, o razonamientos más generales relativos a estos dominios, así como mediante los varios contactos que Flores tiene con los científicos italianos, franceses y españoles. En este artículo, vamos a glosar y analizar dicha dimensión científica del diario de José Felipe Flores, centrándonos primero en lo que descubre en este ámbito durante su estancia en las distintas ciudades por las que pasa y, luego, evocando los contactos del médico chiapaneco en el mundo científico europeo.

18 Véanse en el Anexo 2 los mapas del recorrido de Flores por Italia, Francia y España. Remitimos también a la Introducción a la edición crítica para más informaciones acerca del desarrollo del viaje. 


\section{El viaje y los descubrimientos científicos}

Numéricamente, pocos son los sitios en relación con el dominio científico porque sólo representan unos $15 \%$ de los lugares visitados. Sin embargo, a nivel textual, las reflexiones científicas representan casi el 25\% del manuscrito, y los lugares visitados, aunque poco numerosos, son muy amplia y detalladamente descritos.

Cuando está en La Granja, Flores apunta en su diario sus experimentos y sus reflexiones acerca de la construcción del telescopio, lo que era de esperar en la medida en que la elaboración de dicho instrumento es el objetivo de su colaboración con la Fábrica de Cristales. Alude también a trabajos o estudios preparatorios cuando se halla en París en compañía de miembros del Instituto de Francia ${ }^{19}$. No nos detendremos aquí sobre dichas reflexiones, por ser demasiado específicas y a veces muy crípticas y porque preferimos dar a ver un estado de la cuestión más general.

Más allá de esto, Flores se interesa por numerosos fenómenos relativos al campo del saber científico ${ }^{20}$, como los relacionados con la geología o la climatología, en particular cuando observa los volcanes del área napolitano o el clima, vinculándolo con cuestiones de sanidad pública ${ }^{21}$. Aprovecha sus desplazamientos para visitar varios lugares de desarrollo de la medicina. Por ejemplo, visita hospitales, como los de Florencia, de Nápoles o de Madrid. En las descripciones que hace de éstos en su diario, Flores adopta un tono crítico, alabando las estructuras hospitalarias funcionales, bien equipadas, donde es posible llevar investigaciones para desarrollar los conocimientos médicos, y juzgando a veces de modo muy cínico otros hospitales que se hallan en un estado catastrófico de insalubridad y de poco desarrollo científico, como por ejemplo el Hospital General de Nápoles:

Esto es poca cosa, y nada correspondiente a la grandeza de esta Corte. Lo raro es que se ven casi más médicos y practicantes que enfermos, y el estudio de la fa-

19 Por la Constitución de 1795, se suprimieron las academias reales y fue creado el Instituto de Francia, que reagrupa hasta hoy cinco academias: la Academia Francesa, la Academia de Inscripciones y Lenguas Antiguas, la Academia de Bellas Artes, la Academia de Ciencias Morales y Políticas, y la Academia de Ciencias. De aquí en adelante, seguiremos hablando de la Academia de Ciencias dado que nuestras investigaciones se centran en este ramo del Instituto de Francia. Para una historia de esta institución, véase Roger Hahn, L'anatomie d'une institution scientifique. L'Académie des Sciences de Paris, 1666-1803, Paris, Éditions des Archives Contemporaines, 1993.

20 Véase el Anexo 3 relativo a la lista de los lugares relacionados con el dominio científico visitados por Flores.

${ }_{21}$ Notemos por ejemplo sus varias reflexiones acerca del «Aeria Cativa», enfermedad que se declara en las tierras de clima caliente y húmedo como en ciertas regiones de Italia y del sur de Francia. FLores, Diario, f. 15r. y f. 35v. 
cultad es miserable. Abajo de los hombres hay dos pequeñas salas para unciones, y ara para locos. No se puede ver cosa más asquerosa, ni más fétida. Es necesario que más sirvan de martirio a los miserables que de alivio. ${ }^{22}$

Algunas estructuras se fundan en bases correctas pero muy poco actualizadas y merecerían ser mucho más desarrolladas, como es el caso del Colegio de Cirugía anexo del Hospital General de Madrid, del cual Flores dice:

No hay más que algunas piezas de obstetricia naturales y patológicas, copiadas de las láminas de Camper. Una figura de tamaño natural de los músculos externos, y dos pequeños de lo mismo; todas tres macizas; muy pocas inyecciones, y ordinarias; ninguna corrección; algunas infusiones; se trabajaba un brazo con vasos linfáticos copiando de una lámina. Hace fuerza que se expongan a los errores de las láminas, y a un trabajo largo y pesado, pudiendo modelar y copiar del natural, supuesto que hay Demostrador y Director pagados, no hay ninguna pieza que se desarme: la Sala es pequeña, y así este gabinete está muy a los principios ${ }^{23}$

Y a esto añade:

En una ciudad grande como ésta, sería de desear se abandonase una casa como ésta, más pomposa que útil, y estableciesen en los cuarteles pequeños hospitales bien formados, en que los enfermos estarían mejor tratados, el público con más prontitud servido, y con más adelantamiento de los Profesores. ${ }^{24}$

Flores describe también de manera muy detallada tres centros científicos italianos: el Museo de Física de Florencia, el Monasterio benedictino de Ravena y diversos lugares dedicados a la ciencia en la ciudad de Padua.

Visita el Museo de Física de Florencia el 21 de mayo de 1798. Este centro está dirigido por el físico y naturalista Felice Fontana ${ }^{25}$. Parece impresionarle mucho lo que descubre en él: presenta en detalle nueve objetos concebidos por el físico italiano, entre ellos las estatuas de madera que representan a escala natural los huesos, los músculos y el sistema sanguíneo del ser humano. Estas le interesan más particularmente en la medida en que él también elaboró este tipo de representaciones, pero no de madera sino de cera:

\footnotetext{
$22 \quad$ FLores, Diario, f. 17r-17v. 11 de junio de 1798.

$23 \quad$ Flores, Diario, f. 69v. 5 de mayo de 1801.

24 Flores, Diario, f. 70r. Misma fecha.

25 Véanse notas 47 y 48.
} 
Luego pasé a otro gabinete y me mostró una figura de anatomía que tiene reservada. Es un hombre de buena talla quitados los ligamentos, y se ven los músculos con sus vasos y nervios, y se van desarmando del mismo modo que en mi figura, con la diferencia de que yo trabajé en cera y Fontana en madera, lo que hace su figura más apreciable porque se puede manejar continuamente para el estudio sin que se rompa, ni se ensucie, inconveniente que ha resultado en la mía. Tiene otra ventaja esta figura de Florencia y es que la misma de biología contiene las entrañas, descuerde que, con esta estatua y la osteología, se tiene una anatomía completa, siempre entendiéndose que es preciso un pecho y vientre de mujer. Me mostró allí mismo una cabeza y pecho de hombres de tamaño natural. ${ }^{26}$

Precisamos que a Fontana se lo conoce por haber sido el primero en realizar estas representaciones, pero las cartas de Flores sugieren que él mismo es en realidad el primerísimo en modelarlas ${ }^{27}$. La lectura del diario aporta una prueba más para respaldar esta segunda teoría a favor del médico guatemalteco. Flores se interesa también por las otras actividades de Fontana, y sobre todo por sus trabajos novedosos en el campo naturalista ${ }^{28}$. De este modo, con su diario, Flores contribuye a la difusión de los avances de la ciencia en este dominio.

Casi un mes más tarde, el 26 de junio, Flores visita Ravena y se detiene en el monasterio de los Benedictinos, donde se conservan instrumentos de cirugía y máquinas destinadas a cuidados médicos ${ }^{29}$. Notamos también que en este sitio

26 Flores, Diario, f. 4v. 21 de mayo de 1798

27 Sobre este punto, véase también Aznar López, pág. 49 y MartínEz Durán, págs. 289-290.

28 «Nada me admiró más de este sabio como sus experiencias e ideas sobre el ergot y la tremella. Hace ver en el primero un humor semejante a los que se forman preternatural en las cortezas de los vegetales. Es un nido de serpientes. Esto es común, pero este naturalista los desarrolla, los mata, los revive, los divide, muestra los movimientos espontáneos de las piezas diferentes del movimiento y dirección que resulta de su unión: en fin es un conjunto de fenómenos que le han producido ideas demasiado aventuradas para la metafísica. Es un campo nuevo que se abre a la curiosidad de los hombres a la lucha de sus opiniones y a la ferocidad de sus pasiones. Ha llegado la perspicacia de este hombre hasta demostrar el sexo masculino en un individuo, y el femenino en otro: los huevos, la generación de las serpientes, su propagación, el perecimiento de los padres, etc. Por fortuna ni ha publicado, ni piensa en publicar sus ideas. Las experiencias de las tremella no son menos curiosas y nuevas. Demuestra igualmente que son gusanos largos o serpientes puestas, y colocadas de modo que en donde una tiene la cabeza, otra tiene la cola, sus movimientos, su generación, y su perecimiento no le dejan dudas de que son animales.» Flores, Diario, f. 4v.-5r. 21 de mayo de 1798

29 «Los instrumentos de Cirugía, etc., están en un monasterio de Benedictinos. Un monje, hombre de caridad los procuró, y se tienen para el servicio del hospital, y para todo el público: cualquier particular los pide y usa de ellos. Estos instrumentos se guardan en el monasterio en cuatro pequeñas salas: consisten primero en dos casas con sus almohadas, asiento, y demás comodidades para recibir vapor, y tomar baños de esta especie; segundo, en seis camas, dos que se arman en sillas poltronas, inclinando más o menos la espalda para los enfermos, que sufren en la respiración, como los asmáticos, hidrópicos, etc., dos para inclinar con suavidad al enfermo de un lado a otro, y mudar la ropa, etc., y las otras dos para los amputados de pierna, o muslo 
se halla una sala completamente equipada para la hidroterapia, lo que refleja los avances de la época en este sector de la medicina.

Dos días más tarde, Flores se encuentra en Padua, verdadero centro de desarrollo del saber científico, por la abundancia de instituciones dedicadas a la investigación. En efecto, evoca el Observatorio, la Escuela de Química, la Escuela Veterinaria, la Universidad con la enseñanza de la Física, la Escuela privada de Obstétrica, la enseñanza de la Anatomía en el seno del Hospital, así como el Jardín Botánico. Describe el conjunto de estos sitios mencionando sus puntos fuertes y sus puntos débiles ${ }^{30}$.

Más allá de estas consideraciones, Flores evoca también de manera muy puntual objetos o máquinas que le llaman la atención, como el aerostato ideado y elaborado por Garnerin ${ }^{31}$ o el «submarino» que descubre durante su estancia en París ${ }^{32}$. Notemos al respecto que, según Flores, el gobierno frena a veces el desarrollo científico al no apoyar ni respaldar los descubrimientos de los científicos. Éstos últimos obran sin embargo por el progreso de su país, como por ejemplo el ingeniero Agustín de Betancourt quien, según nuestro viajero, proyecta establecer en España telégrafos de su idea. Por cierto, con este mismo

que tienen todas las comodidades para este caso. [...] Atrás de estas cuatro salas hay una larga, y estrecha en donde está primero un cuartito guarnecido de colchones para los epilépticos; segundo, un cuartito para medios baños, y pediluvios; tercero, un baño a la dupe [sic], o chorro, o fomento; cuarto, un bello baño, de mármol blanco con relieves, con sus robinetes para agua caliente y fría. Este establecimiento, que es casi el único de su especie, y muy apreciable, es una prueba convincente de la suma caridad del fundador, pues se ha procurado hasta una colección de libros harto buena y se franquea a todo el mundo.» FLores, Diario, ff. 27r.-28r.

30 Flores, Diario, ff. 28v.-29v.

31 «Se elevó Garnerin en un balón con un oficial. Había dos receptáculos para llenar el globo, que tenía dos mangas. Cada receptáculo era un baño neumatoquímico bajo el que terminaban, o se introducían los tubos encorvados de dieciséis barriles en los que se ponía el ácido sulfúrico y el hierro. El baño es para que el hidrógeno pase al balón limpio. Los barriles son grandes: mayores que nuestros ordinarios de aguardiente, de la misma madera, y los tubos de hoja de lata. La red es delgada, y cubre todo el globo: éste es de tafetán y embarnizado con aceite de linaza, etc.» FLores, Diario, f. 46v. 14 de agosto de 1799.

32 «Vi este mismo día el modelo de un bote subacuático que por medio de un rehilete de seis aspas, uno un poco abajo de la proa, y el otro abajo de la popa, anda adelante o atrás. Abajo de los rehiletes lleva una especie de cola de pato que se mueve para arriba y para abajo, y este movimiento hace subir al bote o bajar. Esta misma cola de pato se mueve a un lado y a otro, y dirige al barco. Hacia a la popa tiene una escotilla, con su puerta, por donde se entra. En esta escotilla hay dos ventanitas con sus vidrios, y una con válvula, para sacar la boca de un cañón o un barreno. Sobre el barco hay una caja larga para guardar una vela latina que sirve cuando el bote navega sobre la agua, y cuando se sume, después de doblar la vela y guardarla, se introduce agua en un receptáculo que tiene el bote por debajo y teniendo entonces más gravedad que igual volumen de agua, el barco se sumerge; si se extrae esta agua toda, el barco flota, y si se saca en parte sube el barco a proporción. Para graduarse, tiene cerca de la bomba neumática que introduce y saca la agua, un tubo de cristal cuya punta abierta entra en el mar, y subiendo en él la agua más o menos, nota la distancia en que se halla el bote de la flor del agua. Esta máquina neumática, y las cigüeñas que por medio de piñones y ruedas mueven los rehiletes y la cola de pato, van en el cuerpo del bote. Este barco se ha inventado para barrenar y volar los navíos en el mar sin recurso. El inventor lo ha propuesto al Gobierno, pero hasta ahora no se ha querido admitir» FloRes, Diario, f. 50v.-51r. 27 de septiembre de 1798. La cursiva es nuestra. 
ingeniero, Flores va a visitar una fábrica de instrumentos de Óptica en París ${ }^{33}$, lo que le va a permitir desarrollar sus investigaciones personales para la elaboración de su telescopio.

No obstante, Flores no se limita a evocar o describir artefactos o lugares propicios al desarrollo y a la difusión del saber científico, o vinculados con el avance de su propio trabajo. Menciona también de forma bastante recurrente los nombres de sus interlocutores, así como sus trabajos.

\section{Los contactos de Flores en el mundo científico europeo}

Según las informaciones contenidas en su diario, José Felipe Flores entra en contacto con diecinueve científicos, sobre todo durante su estancia en Florencia, en Padua y en París, lo que representa casi un tercio de las personas mencionadas en su diario ${ }^{34}$.

Sin embargo, rara vez explica cómo inicia sus contactos con los hombres de ciencia aquí enlistados. Sabemos, gracias a la lectura de la entrada del diario que corresponde al día 20 de mayo de 1798, que Flores conoce al italiano Felice Fontana gracias al exjesuita don Estaban Arteaga, quien hace de intermedio ( Esta noche Don Esteban Arteaga exjesuita, me hizo conocer en un café a Fontana.» ${ }^{35}$ ). En este café florentino, conoce también a Giuseppe Morosi y al doctor Querenti ${ }^{36}$, quienes participan en la misma conversación con Fontana. El 8 de mayo de 1799, cuando Flores está en París, se encuentra con Jean-Baptiste Le Roy siguiendo los consejos de Antonio Gimbernat ${ }^{37}$, con quien tiene varios $\operatorname{contactos}^{38}$. Podemos pues suponer que a algunos hombres de ciencia los conoce Flores mediante vínculos de sociabilidad y círculos de amigos o de conocidos comunes, pero de momento no podemos confirmar tal hipótesis para todas las personas con las cuales se encuentra. En efecto, como es de esperar con un diario, las informaciones en él apuntadas las elige su autor. Nos enfrentamos aquí con uno de los límites del género, con la imposibilidad nuestra de contestar ciertas preguntas basándonos

33 «Una fábrica de instrumentos de Óptica, en donde se hacen porción de lunetas acromáticas.» FLORES, Diario, f. 46r. 9 de agosto de 1799.

34 Hemos realizado un listado de todas las personas mencionadas en el diario de Flores, personas que pueden ser el conductor de su carruaje como otros de mayor relevancia, solo citadas (como el Gran Duque de Toscana) o personas con quienes Flores mantuvo contactos bastante más desarrollados.

35 Flores, Diario, f. 2v. 20 de mayo de 1798.

36 Véanse notas 49 y 57.

37 Flores, Diario, f. 52v. Véase nota 56.

38 Véase nota 61. 
estrictamente en este manuscrito. Desafortunadamente, hasta el momento, no hemos podido localizar documentos complementarios que hubieran podido llenar los espacios en blanco en cuanto a los contactos de Flores en el mundo científico europeo.

En todo caso, lo que sí podemos afirmar es que cada científico con el que contacta el doctor Flores tiene vínculos con academias y sociedades sabias, a través de las cuales se relacionan con otros sabios y se benefician de los avances en el campo del saber científico.

En Italia, los científicos con quienes se encuentra Flores pertenecen a tres Academias en particular: la Academia Nacional de las Ciencias, la Academia de las Ciencias de Padua y la Nueva Academia del Experimento, también conocida como Nuova Accademia del Cimento. Así Flores menciona a seis científicos que pertenecen a estas instituciones:

- Marco Carburi: botánico y químico, Flores se encuentra con él en Padua el 26 de junio de $1798^{39}$. Es miembro de la Academia de las Ciencias de Padua ${ }^{40}$.

- Simone Stratico: también encontrado en Padua el 26 de junio de 1798, es matemático y físico ${ }^{41}$. Es a la vez miembro de la Academia de las Ciencias de Padua y de la Academia Nacional de las Ciencias ${ }^{42}$.

- Michele Vincenzo Malacarne, miembro de estas dos academias ${ }^{43}$, es anatomista y cirujano. Como los dos científicos precedentes, Flores lo conoce en Padua ${ }^{44}$.

- El director del Observatorio astronómico de Padua, Vincenzo Chiminello, miembro de la Academia Nacional de las Ciencias ${ }^{45}$, encontrado como los precedentes el 26 de junio de $1798^{46}$.

\footnotetext{
39 «Vista de la Scuola Chemie del museo Patavino [...]. El Prof. es Carburi.» FLores, Diario, f. 28v.

40 «Marco Carburi», Dizionario Biografico degli Italiani, http://www.treccani.it/enciclopedia/marcocarburi_(Dizionario-Biografico) [última consulta: 11.11.2019]

41 «Junto a esta sala [de Física] y de modo que el conductor del disco grande llegue hasta la mesa, está el anfiteatro donde se hacen las experiencias y se dan las lecciones. El Profesor es Simone Stratico.» Flores, Diario, f. 29r.

42 «Simone Stratico», Dizionario Biografico degli Italiani, http://www.treccani.it/enciclopedia/simone-filippo-stratico \%28Dizionario-Biografico\%29/ [última consulta: 11.11.2019]

43 «Michele Vincenzo Malacarne», Dizionario Biografico degli Italiani, http://www.treccani.it/enciclopedia/vincenzo-malacarne_(Dizionario-Biografico) [última consulta: 11.11.2019]

44 «El profesor Malacarne es uno de los primeros médicos de este Hospital, y profesa la Anatomía.» Flores, Diario, f. 29v.

45 «Vincenzo Chiminello», Dizionario Biografico degli Italiani, http://www.treccani.it/enciclopedia/ vincenzo-chiminello (Dizionario-Biografico)/ [última consulta: 11.11.2019]

46 «Vista del Observatorio astronómico [...]. El Profesor es Chiminello.» Flores, Diario, f. 28v.
} 
- Felice Fontana, miembro de numerosas academias, entre las cuales la Academia Nacional de las Ciencias y la Nuova Accademia del Ci$m e_{t o}{ }^{47}$. Es el científico italiano del cual más habla Flores en su diario, en las entradas que corresponden al 20 y al 21 de mayo de 1798 , cuando el médico está en Florencia ${ }^{48}$.

- Giuseppe Morosi, encontrado en Florencia gracias a Felice Fontana ${ }^{49}$. Es físico mecánico y miembro, como Fontana, de la Nuova Accademia del Cimento. Durante un viaje a París, frecuenta, entre otros lugares, la Academia de las Ciencias ${ }^{50}$, y se lo presentan, entre otros, a Jérôme de La Lande.

En Suiza, Flores se encuentra con el físico, geólogo y naturalista Horace Bénédict de Saussure ${ }^{51}$, de ilustre descendencia. Éste es miembro de la Sociedad de las Artes de Ginebra, de la Royal Society de Londres, pero es también socio extranjero de la Academia de las Ciencias de París ${ }^{52}$.

En París, Flores frecuenta esta Academia, sin por ello ser miembro, y menciona a seis de sus académicos:

- Abraham-Louis Bréguet: Flores visita al físico, ingeniero y relojero en París los días 11 y 12 de agosto de $1798^{53}$.

- Jacques Charles. Flores asiste a la clase del geómetra y físico en el Louvre el 1 de diciembre de $1798^{54}$.

47 «Gasparo Ferdinando Felice Fontana», Dizionario Biografico degli Italiani, http://www.treccani.it/ enciclopedia/gasparo-ferdinando-felice-fontana_(Dizionario-Biografico) [última consulta: 11.11.2019]

48 «me hizo conocer en un café a Fontana, y tuve esta satisfacción; es un hombre como de poco más de sesenta, trigueño, algo grosero y harto parecido en las facciones a nuestro Señor Miguel Asturias. Estuvimos en conversación, y me prometió que me haría ver sus instrumentos de física, etc. Jamás ha sido clérigo ni abate. [...] 21. Visita del museo de Física: el mismo Félix Fontana me enseñó y explicó la construcción y uso de muchos de sus instrumentos. Estos no son los comunes, ni conocidos: son la mayor parte inventados por el genio raro de este hombre.» FLORES, Diario, f. $2 \mathrm{v}$.

49 «Conocí al Señor Morosi que ha construido un autómata que juega al ajedrez.» FLores, Diario, f. 2v.

50 « Giuseppe Morosi », Dizionario Biografico degli Italiani, http://www.treccani.it/enciclopedia/ giuseppe-morosi_(Dizionario-Biografico)/ [última consulta: 11.11.2019]

51 «El profesor Saussure está viviendo en la campaña.» Flores, Diario, f. 38v.

52 Douglas William Freshfield, Horace-Bénédict de Saussure, Genève, Slatkine, 1989, p. 360.

53 «11. Visité a Bréguet, y vi muestras de un extremo primor, no sólo por su forma elegante, sino por la perfección de su fábrica: en la que este célebre Mecánico, hoy sin disputa merece una notable preferencia. Vi un moderador de su invención, que no es más que una espina, que no recibiendo casi movimiento del resorte, infunde la mayor igualdad en el movimiento de la máquina. Este nuevo balancero arregla las muestras que se le ponen sobre una media luna que tiene encima, lo vi ejecutarse dos veces. 12. Segunda visita a Bréguet y compra de las muestras.» Flores, Diario, f. 46v.

54 «Comenzó el curso de Física, Charles en el Louvre. Se abrió con un discurso, comenzando por el conocimiento del Criador. Se siguió con la historia de la Física, y se terminó con el orden de las lecciones, que es el ordinario de todos los cursos.» FLOREs, Diario, f. 5lv. 
- Antoine-François Fourcroy. Flores asiste a sus clases y experiencias los días 11 y 31 de diciembre de $1798^{55}$.

- Jacques Antoine Joseph Cousin, Presidente de la Academia durante el segundo semestre del Año VII, o sea de finales de marzo a finales de septiembre de 1799.

- Jérôme Joseph Lefrançois de La Lande, astrónomo.

- Jean-Baptiste Le Roy, Geómetra y mecánico. Flores se encuentra con estos tres últimos para la presentación de un telescopio que concibió. Se encuentra con Le Roy el 8 de mayo de 1799, y se reúne de nuevo con él, con Cousin y La Lande, el 25 de mayo ${ }^{56}$.

Además de estos científicos que pertenecen a las cuatro redes compuestas mediante las academias italianas y parisina, José Felipe Flores entra también en contacto con otros seis científicos. Por orden de aparición:

- el doctor Querenti, químico italiano, frecuentado en Florencia los días 20 y 21 de mayo de $1798^{57}$,

- Antonio Rinaldini, naturalista y profesor de la Escuela Veterinaria de Padua, encontrado el 28 de junio de $1798^{58}$.

- Agustín de Betancourt. Flores se encuentra con el ingeniero español en París el 9 de agosto de $1798^{59}$, con el que visita una fábrica de instrumentos de óptica, útiles para la elaboración de su telescopio.

55 «11. Hoy comenzó Fourcroy su curso de Química, en su laboratorio con un discurso preliminar, en que refirió la historia de esta ciencia y su última revolución.» Flores, Diario, f. 51v. «31. Este día el frío era de catorce bajo el cero y Fourcroy mezcló en un mortero de piedra hielo y muriate de cal el frío de treinta y seis a cuarenta y heló una ampolla de mercurio se quebró la ampollita y el azogue quedó helado, como una bola de estaño; era algo maleable.» Flores, Diario, f. 51v.

56 «15. Hoy en la Junta del Instituto, se presentó el telescopio por el C. Le Roy. Me condujo con el instrumento al medio de la Asamblea en donde está una mesa de mármol negro, sobre la que expuse el telescopio. Le Roy hizo al Presidente la relación, y éste nombró una comisión compuesta del mismo Le Roy y de La Lande. [...] El día 8 por dirección del Amigo Gimbernat, llevé, y mostré mi telescopio a Le Roy, el que habiéndose inteligenciado de la calidad del espejo lo halló digno de presentarlo al instituto. Le Roy es el antiguo académico de las Ciencias, hombre viejo y muy amable.» Flores, Diario, f. $52 \mathrm{r}-52 \mathrm{v}$.

57 «Conocí allí mismo al Doctor Querenti autor de las experiencias de la aplicación de varios simples, disueltos en el suco gástrico, por fricciones.» Flores, Diario, f. 2v. «Nos prometimos correspondencia y nos despedimos. Hice el mismo cumplimiento al Doctor Querenti, y me regaló su libro de experiencias sobre la digestión y usos del suco gástrico.» Flores, Diario, f. 5r.

58 «El profesor de Veterinaria Antonio Rinaldini.» Flores, Diario, f. 28v.

59 «De aquí fui con el Doctor Betancourt, español de Canarias, célebre mecánico, a ver una fábrica de instrumentos de Óptica, en donde se hacen porción de lunetas acromáticas para ir a establecer a España Telégrafos de su invención, y más simples y fáciles que los que hoy se usan.» Flores, Diario, f. 46r. 
- El aeronauta francés André-Jacques Garnerin, al que Flores ve elevarse en aerostato en París el 14 de agosto de $1798^{60}$.

- Antonio Gimbernat, anatomista y cirujano español. Aparece 3 veces en el diario de Flores: Flores lo menciona el 8 de mayo de 1799, cuando está en París y, siguiendo los consejos de Gimbernat, se encuentra con Jean-Baptiste Le Roy. Ambos se encuentran el 12 de agosto de 1799 en La Granja, y tres días más tarde en Madrid ${ }^{61}$.

- Para terminar, Juan López Peñalver. Flores menciona al ingeniero y economista español el 9 de marzo de 1801 y lo encuentra el 21 del mismo mes $^{62}$.

Algunos de estos hombres de ciencia pertenecen también a otras academias y sociedades científicas, distintas de las cuatro antes evocadas. Otros frecuentan también estos círculos sin por ello ser miembros, como es el caso por ejemplo de Giuseppe Morosi con la Academia de las Ciencias, el Observatorio y el Conservatorio de Artes y Oficios de París, o como el mismísimo Flores, quien frecuenta la Academia de las Ciencias de París. Al observar más detenidamente las afiliaciones de estos científicos, podemos darnos cuenta de que estos círculos a veces se entrecruzan, y que los nombres de ciertas academias o sociedades aparecen de manera recurrente. Por ejemplo, numerosas conexiones se establecen en torno a la Royal Society de Londres. Asimismo, algunos sabios se encuentran ligados a través de la Academia de las Ciencias de Turín, las de Baviera y de San Petersburgo, o por su relación con el Collège de France.

Por otro lado, varios científicos se relacionan con otras academias y sociedades europeas, como en París, en España con la Real Sociedad Bascongada de los Amigos del País, o en Alemania. Algunos tienen también vínculos con instituciones científicas estadounidenses o rusas, como por ejemplo Jean-Baptiste Le Roy o Antoine-François Fourcroy.

60 «14. A la tarde al jardín de las Capuchinas, hoy de Apolo. Se elevó Garnerin en un balón con un oficial. Había dos receptáculos para llenar el globo, que tenía dos mangas. Cada receptáculo era un baño neumatoquímico bajo el que terminaban, o se introducían los tubos encorvados de dieciséis barriles en los que se ponía el ácido sulfúrico y el hierro. El baño es para que el hidrógeno pase al balón limpio. Los barriles son grandes: mayores que nuestros ordinarios de aguardiente, de la misma madera, y los tubos de hoja de lata. La red es delgada, y cubre todo el globo: éste es de tafetán y embarnizado con aceite de linaza, etc.» FLores, Diario, f. 46v.

61 «12. Don Antonio Gimbernat me previno el orden del Ministro, que temiendo que el espejo de veinticuatro pulgadas fuese muy costoso, lo quería consultar con los Directores del Observatorio, y en consecuencia al día siguiente.» Flores, Diario, f. 58r. «15. Gimbernat por la mañana fue a pedirme el espejo de cuatro pulgadas para enseñarlo al Ministro, diciendo que quería verlo.» FLores, Diario, f. 59r.

62 «9. Nueva orden para me retornase, y mostrase los espejos a Peñalver, y por la tarde volví a sacarlos al puente. [...] 12. Vino Peñalver y no los espejos y vidrios.» Flores, Diario, f. 69r. 


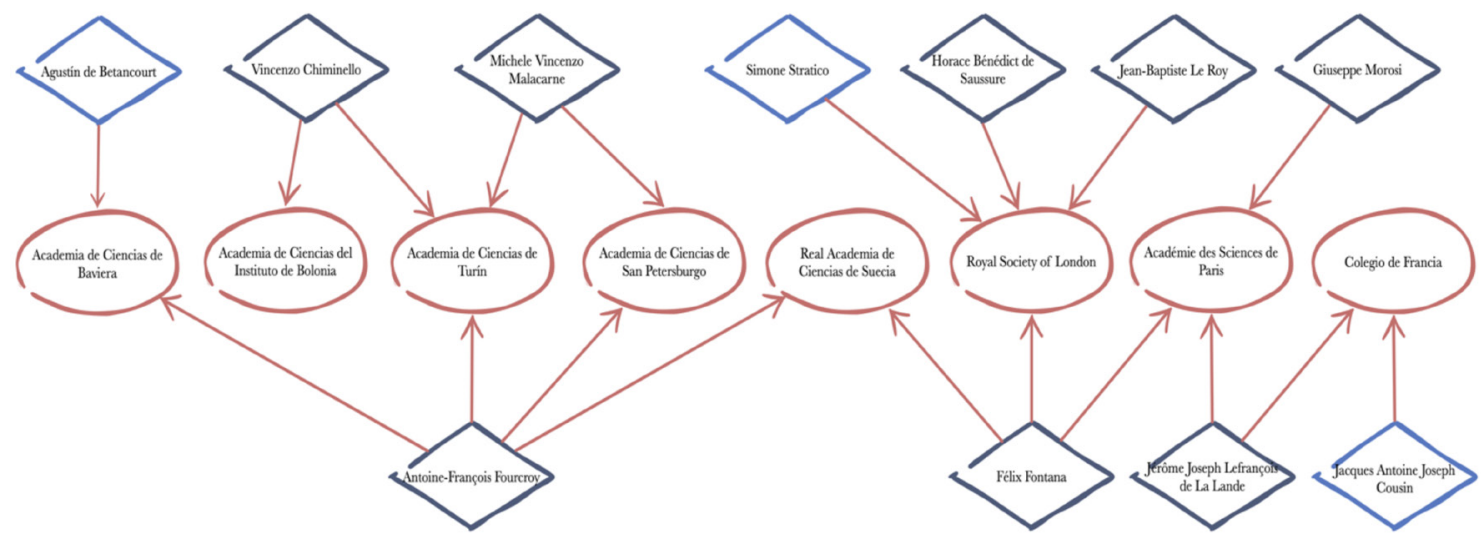

Fig. 2. Entrecruces de circuitos

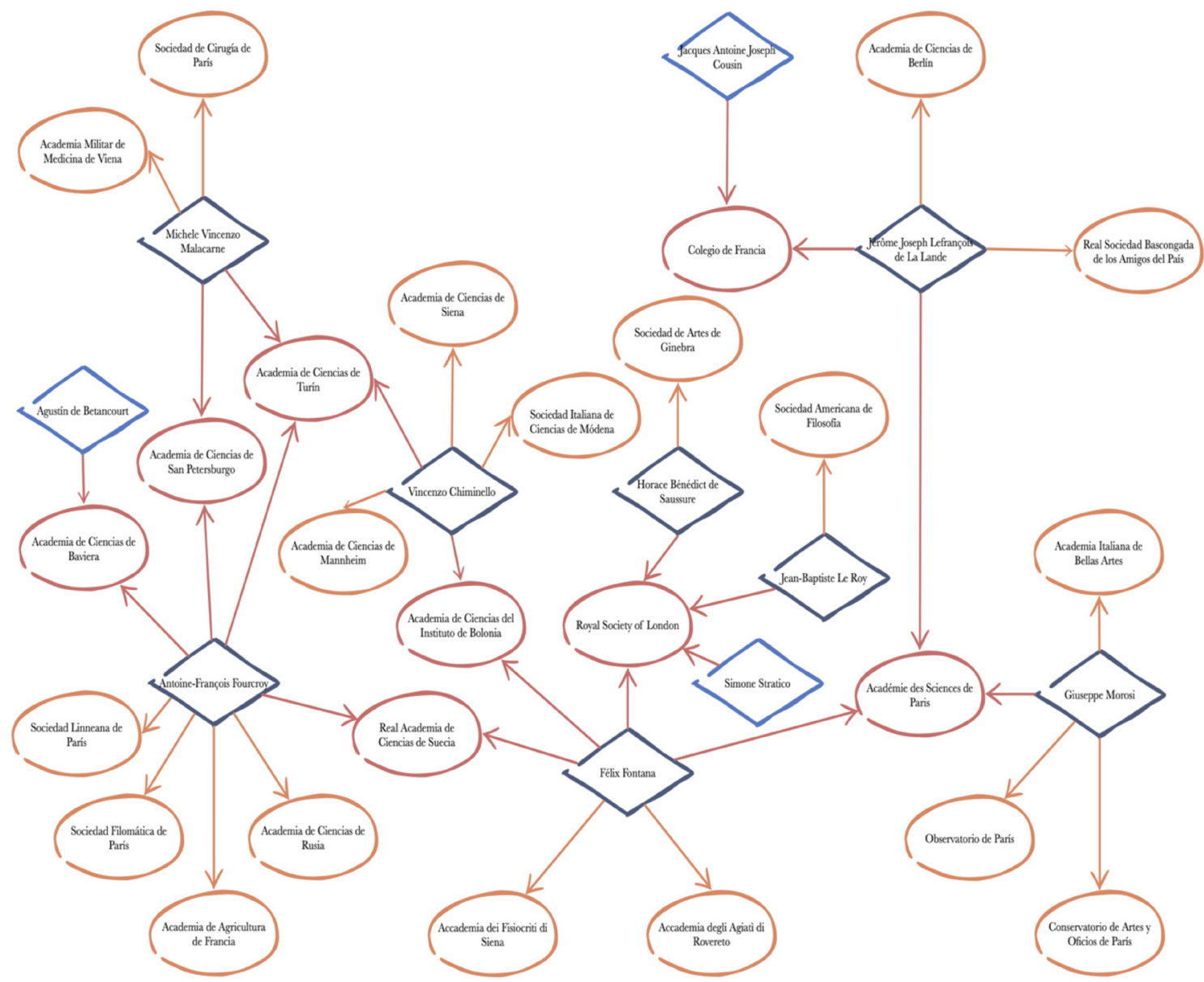

Fig. 3. Otras ramificaciones 
Podemos pues comprobar que muchas redes se entrecruzan y que numerosos interlocutores de Flores tienen en común el pertenecer a varias academias o sociedades, y que esta red tiene numerosas ramificaciones, lo que permite desarrollar y amplificar la recepción y la difusión de los conocimientos, en Europa y más allá. Las conexiones establecidas por Flores durante su viaje son pues plenamente representativas de los vínculos que unen a los diversos círculos del saber de su época.

Se trata aquí de un conjunto que puede parecer algo restringido, pero recordamos que sólo observamos la configuración de la red científica de Flores, y no su red en su conjunto, y que sólo podemos basar nuestra investigación en la última parte de su diario, es decir la única que conocemos. Es pues muy probable que Flores se inserte en un esquema mucho más amplio. Sin embargo, de momento, no hemos podido comprobar, por falta de suficientes pruebas documentales, el dinamismo de dichas redes. Tampoco podemos saber si el médico consiguió mantenerlas activas una vez instalado en La Granja (el único ejemplo que tenemos de ello es el de Antonio Gimbernat, con contactos en París, en La Granja y en Madrid en distintas fechas del año de 1799).

\section{Conclusiones}

Flores acaba la redacción de su diario el 23 de noviembre de 1802 . Ha conseguido llevar a cabo la realización de su telescopio y tiene previsto volver a Guatemala, lo que al final no hace nunca, ya que sus estancias prolongadas en París suscitan el miedo a un «contagio revolucionario» hacia América y la licencia para su regreso en realidad nunca le es concedida.

Volvemos a saber de él algunos años más tarde en Sevilla y en Cádiz. Sigue con sus experimentos en diversos dominios y publica en 1811 un memorial sobre la conservación de los alimentos: Experimentos sobre la conservación de las carnes $^{63}$.

Sin embargo, arrancado a su tierra natal, sus apoyos van disminuyendo, así como sus recursos financieros, que mayoritariamente se originan en Guatemala. Su situación empeora aún más después de la independencia de su patria chica en septiembre de 1821. Flores muere en Madrid en 1824 después de años lidiando con la pobreza y luchando para recuperar los emolumentos a que tenía derecho.

Aunque fue objeto de atención por parte de médicos e historiadores, y aunque se beneficia de cierta resonancia todavía hoy en Guatemala, algunas facetas

63 FLoREs, Experimentos sobre la conservación de las carnes, Cádiz, [s.e.], 1811. 
de la vida de este personaje desdichado y desvalido quedan desconocidas o incompletas. Seguimos con nuestras investigaciones para poder intentar llenar los espacios en blanco. Con el descubrimiento que constituye este diario inédito y con su estudio en este artículo y en publicaciones futuras, esperamos contribuir a aclarar las cuestiones que siguen planteándose, así como restablecer algunas verdades sobre su vida para devolverle algo del lustre que se merece. 


\section{Anexo 1}

Portada del manuscrito 17730 de la Biblioteca Nacional de España

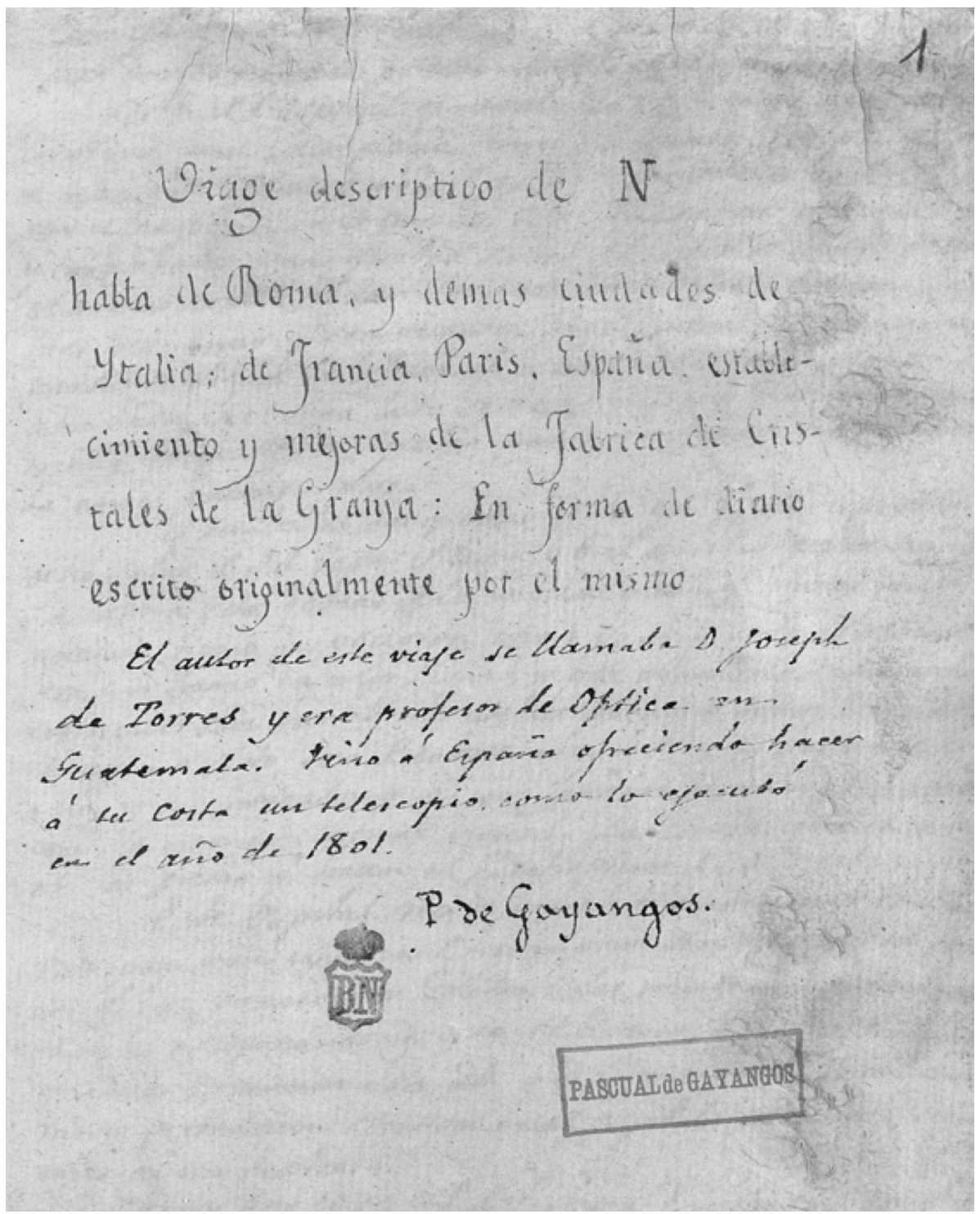


Anexo 2.

Recorrido de José Felipe Flores por Italia, Francia y España

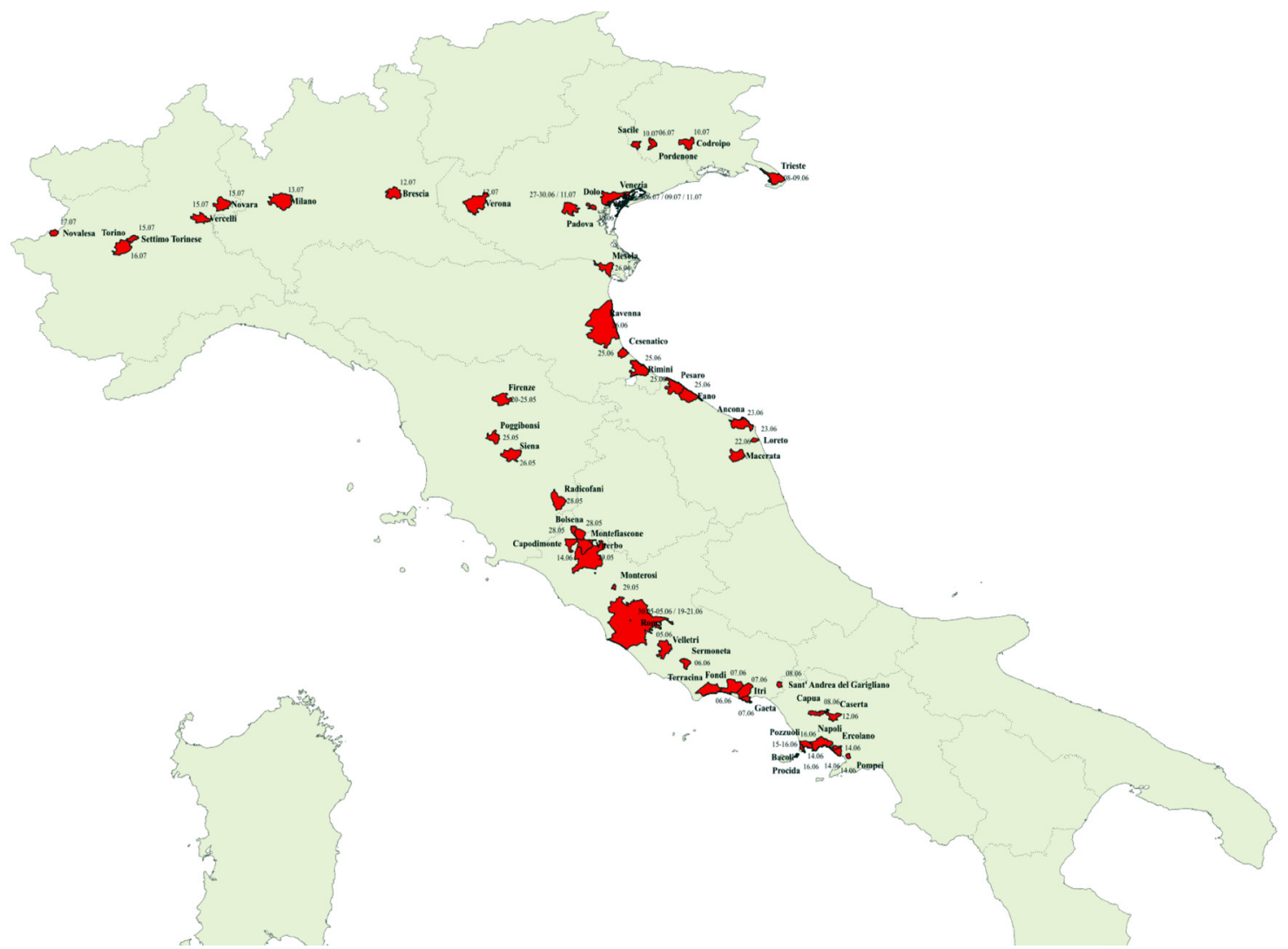

Mapa 1. Recorrido de Flores por Italia (1798) 


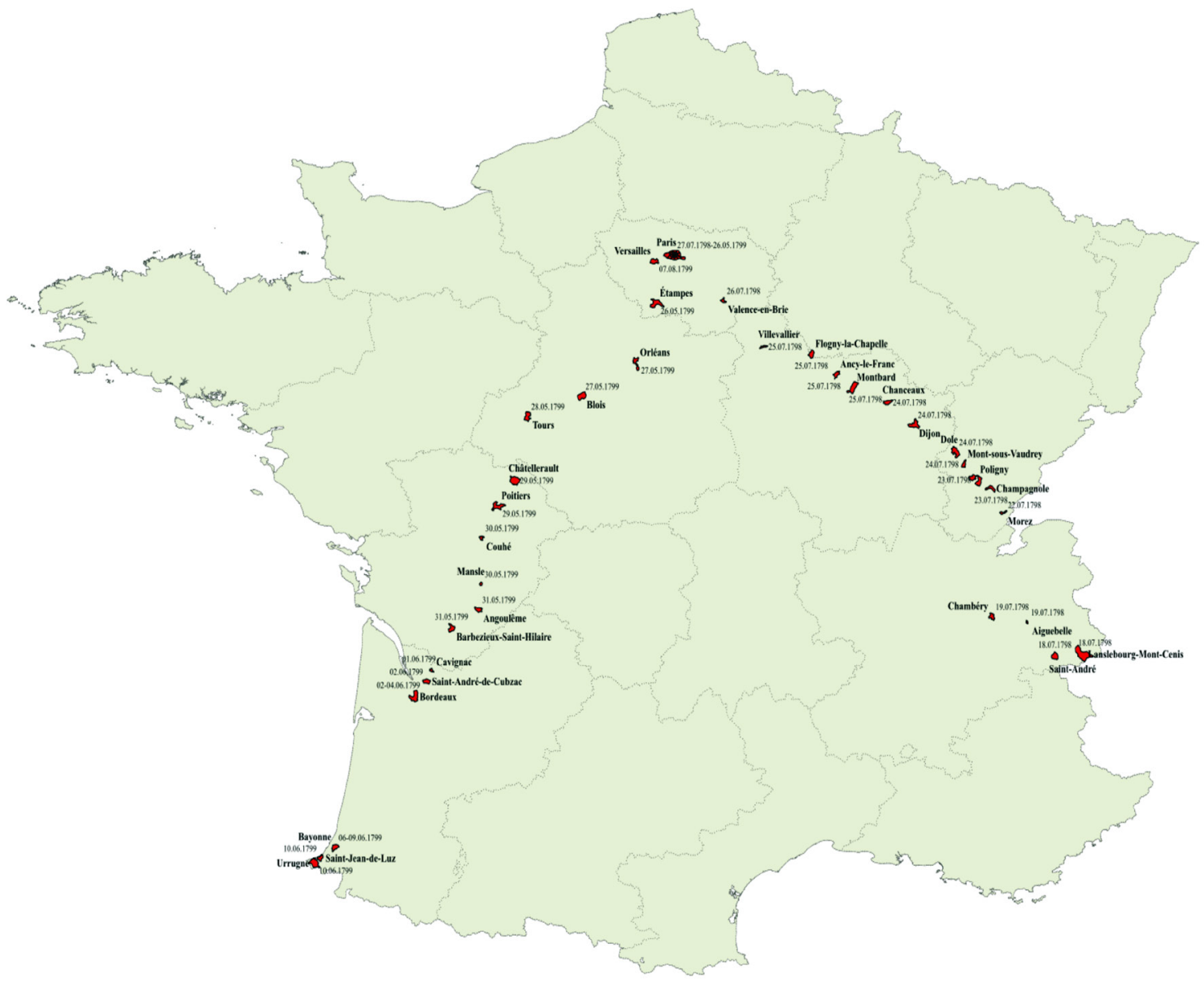

Mapa 2. Recorrido de Flores por Francia (1798-1799) 


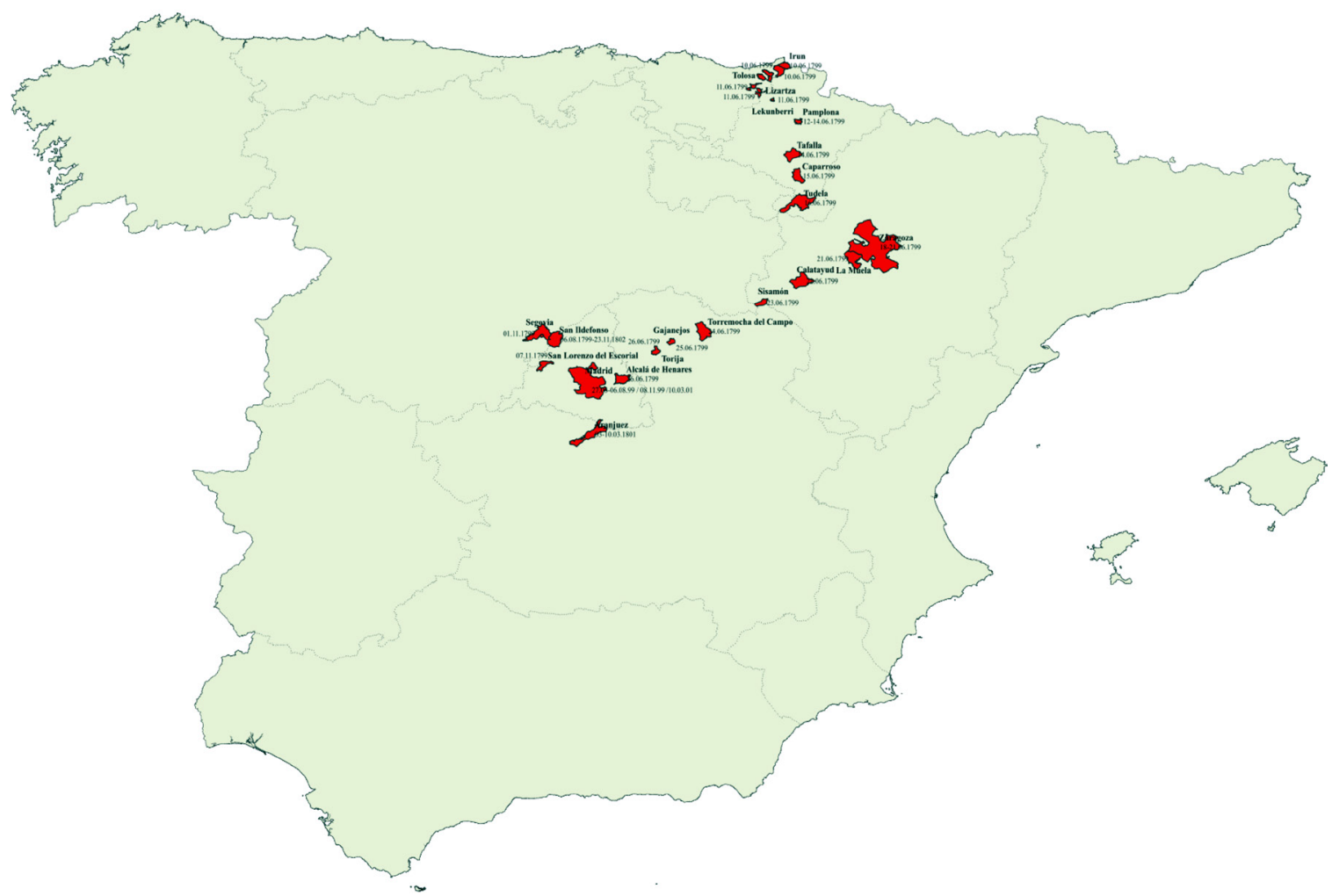

Mapa 3. Recorrido de Flores por España (1799-1802) 


\section{Anexo 3}

Los lugares relativos a las ciencias visitados por José Felipe Flores Y MENCIONADOS EN SU DIARIO

\begin{tabular}{|r|l|}
\hline 1 & Hospital General \\
2 & Museo de Física \\
\hline 3 & Hospital del Sancti Spiritus \\
\hline 4 & Universidad \\
\hline 5 & Hospital de los incurables \\
\hline 6 & Hospital de Santiago de los Españoles \\
\hline 7 & Lago Agnano \\
\hline 8 & Estufas de San Germán \\
\hline 9 & Pozo Pisciarelli \\
\hline 10 & Sulfatara \\
\hline 11 & Lago Averno \\
\hline 12 & Hospital \\
\hline 13 & Monasterio de Benedictinos \\
\hline 14 & Hospital nuevo \\
\hline 15 & Observatorio Astronómico \\
\hline 16 & Escuela de Química \\
\hline 17 & Escuela Veterinaria \\
\hline 18 & Universidad \\
\hline 19 & Escuela privada de Obstetricia \\
\hline 20 & Jardín Botánico \\
\hline 21 & Fábrica de instrumentos de óptica \\
\hline 22 & Louvre \\
\hline 23 & Biblioteca \\
\hline 24 & Laboratorio de Foureroy \\
\hline 25 & Instituto de Francia (Academia de Ciencias) \\
\hline 26 & Universidad \\
\hline 27 & Veterinaria \\
\hline 28 & Hospicio \\
\hline 29 & Colegio de Cirugía \\
\hline 30 & Hospital General \\
\hline
\end{tabular}

\begin{tabular}{|c|c|}
\hline 20.05.1798 & Florencia \\
\hline 21.05.1798 & Florencia \\
\hline $01.06 .1798-04.06 .1798$ & Roma \\
\hline 11.06 .1798 & Nápoles \\
\hline 11.06.1798 & Nápoles \\
\hline 11.06 .1798 & Nápoles \\
\hline 15.06.1798 & Agnano \\
\hline 15.06.1798 & Agnano \\
\hline 15.06.1798 & Agnano \\
\hline 15.06.1798 & Pozzuoli \\
\hline 16.06 .1798 & Pozzuoli - Baia \\
\hline 26.06 .1798 & Ravena \\
\hline 26.06.1798 & Ravena \\
\hline 28.06.1798 & Padua \\
\hline 28.06.1798 & Padua \\
\hline 28.06.1798 & Padua \\
\hline 28.06.1798 & Padua \\
\hline 28.06.1798 & Padua \\
\hline 28.06.1798 & Padua \\
\hline 28.06.1798 & Padua \\
\hline 09.08 .1798 & Paris \\
\hline $\begin{array}{c}10.08 .1798-22.09 .1798- \\
01.12 .1798\end{array}$ & Paris \\
\hline 12.08 .1798 & Paris \\
\hline 11.12 .1798 & Paris \\
\hline 15.05.1799 & Paris \\
\hline 26.06.1799 & Alcalá \\
\hline 10.02 .1801 & Madrid \\
\hline 12.02 .1801 & La Granja? \\
\hline 05.05 .1801 & Madrid \\
\hline 05.05 .1801 & Madrid \\
\hline
\end{tabular}

